\title{
Optimizing RNA Extraction of Renal Papilla Biopsy Tissue in Kidney Stone Formers: A New Methodology for Genomic Study
}

\author{
Kazumi Taguchi, MD, PhD,,2 Manint Usawachintachit, MD, ${ }^{1,3}$ Shuzo Hamamoto, MD, PhD, Rei Unno, MD, \\ David T. Tzou, MD, Benjamin A. Sherer, MD, Yongmei Wang, MD, PhD, Atsushi Okada, MD, PhD, \\ Marshall L. Stoller, MD, Takahiro Yasui, MD, $\mathrm{PhD}^{2}$, and Thomas Chi, MD ${ }^{1}$
}

\begin{abstract}
Introduction: Endoscopic tools have provided versatile examination and treatment for kidney stone procedures. Despite endourologists researching urinary stone disease using endoscopes to collect tissue, this tissue collection method is limited. Endoscopically removed tissues are small in size, restricting the types of genomebased examination possible. We investigated a new method of renal papilla biopsy and RNA extraction to establish a genomic research methodology for kidney stone disease.

Patients and Methods: We conducted a prospective multi-institutional study and collected renal papilla specimens from consecutive percutaneous nephrolithotomy and ureteroscopy (URS) cases performed for removal of upper urinary tract stones. Renal papilla tissue was extracted using ureteroscopic biopsy forceps after stone removal. RNA was extracted using two different extraction kits, and their quantity and quality were examined. Additionally, the impact of biopsy on surgical complications was compared between cases performed with and without biopsy by matched case-control analysis adjusted for age, gender, body mass index, bilaterality, and stone burden.

Results: A total of 90 biopsies from 49 patients were performed, and the median duration between specimen collection and RNA extraction was 61 days. Both univariate and multivariate analyses showed BIGopsy ${ }^{\circledR}$ forceps usage significantly increased the total yield $(p=0.004)$ and quality ( $p=0.001$ for A260/280, $p=0.004$ for A260/ A230) of extracted RNA. Extraction using the RNeasy Micro Kit ${ }^{\circledR}$ also improved A260/A230, whereas reduced RNA integrity number of extracted RNA by univariate and multivariate analyses $(p=0.002$ and $p<0.001$, respectively). Moreover, matched case-control study demonstrated that endoscopic renal papilla biopsy caused no significant surgical complications, including bleeding, decreased stone clearance and hematocrit, and renal dysfunction. Biopsies during URS imparted an average of 20 minutes of procedure time over nonbiopsy cases.

Conclusions: We demonstrate a safe methodology for optimal RNA extraction of renal papilla tissue. This technique will accelerate advanced genomic studies for kidney stone formers by facilitating larger tissue yields.
\end{abstract}

Keywords: kidney stone disease, percutaneous nephrolithotomy, ureteroscopy, RNA extraction, Randall's plaque, renal papilla biopsy

\section{Introduction}

W HILE THE PREVALENCE of kidney stones is rapidly increasing, ${ }^{1}$ the pathogenesis of stone formation is still poorly understood. Previous publications have implicated some genetic triggers related to stone formation, including single nucleotide polymorphisms. ${ }^{2,3}$ In most instances for genetic studies, samples are limited to urine, blood, and stone fragments for investigation of lithogenesis. The absence of live renal tissue makes it difficult to directly investigate pathophysiological features of stone-forming cells.

Advancement in flexible ureteroscopy (URS) and percutaneous nephrolithotomy (PCNL) instrumentation utilized in these procedures have provided a better visualization of the

\footnotetext{
${ }^{1}$ Department of Urology, University of California, San Francisco, San Francisco, California.

${ }^{2}$ Department of Nephro-urology, Nagoya City University Graduate School of Medical Sciences, Nagoya, Japan.

${ }^{3}$ Division of Urology, Faculty of Medicine, Chulalongkorn University, King Chulalongkorn Memorial Hospital, The Thai Red Cross Society, Bangkok, Thailand.

${ }^{4}$ Endocrine Research Unit, Veterans Affairs Medical Center, San Francisco and University of California, San Francisco, California.
} 
upper urinary tract and lead to a high stone-free rate. ${ }^{4-6}$ In addition to clinical care improvement, the improved endoscopic view has also advanced basic translational and clinical research. ${ }^{7,8}$ Nevertheless, one remaining challenge is the limited amount of papillary tissue that can be collected endoscopically. Both the quality and quantity of tissue specimens are crucial to perform genomic experiments.

We previously reported on gene expression of renal papilla tissue around Randall's Plaques (RP), ${ }^{9}$ which were consistently seen both in vitro ${ }^{10,11}$ and in vivo. ${ }^{12}$ While conducting this previous research, we faced the challenge of poor tissue quality and small sample yield. To overcome this obstacle, we investigated a new method of renal papilla biopsy and RNA extraction for kidney stone research.

\section{Patients and Methods}

\section{Prospective cohort study design}

This was a prospective multicenter study conducted at four institutions located in Japan and the United States, Nagoya City University (NCU), and University of California, San Francisco (UCSF). Institutional Review Board approvals were obtained from the two coordinating sites: NCU (No. 929) and UCSF (CHR 14-14533). During the study period between September 2014 and August 2016, we included patients between 18 and 80 years of age with upper urinary tract stones requiring URS or PCNL procedures, all of whom provided written consent to participate. We excluded patients who were pregnant, previously diagnosed with cancer, had active urinary tract infection, complex anatomy of the upper urinary tract, complete staghorn stone, systemic disease, or severe comorbidity (greater than ASA III).

Four endourologists performed the endoscopic procedures in this study. For URS, K.T. and S.H. utilized reusable flexible ureteroscopes (Flex- $\mathrm{X}^{2 \mathrm{TM}}$, Karl Storz, Tuttlingen, Germany, or URF-V ${ }^{\mathrm{TM}}$, Olympus, Tokyo, Japan), and M.S. and T.C. utilized either reusable (URF-P6 ${ }^{\mathrm{TM}}$, Olympus) or disposable flexible ureteroscopes (LithoVue ${ }^{\mathrm{TM}}$, Boston Scientific, Marlborough, MA). For PCNL, all procedures were performed in the prone position with either a $19.5 \mathrm{~F}$ percutaneous nephroscope (Karl Storz) or 24F rigid offset nephroscope (Richard Wolf Medical, Knittlingen, Germany) and lithotripsy was performed with Swiss LithoClast ${ }^{\circledR}$ (Boston Scientific) or UreTron ${ }^{\circledR}$ (Med-Sonics, Erie, PA) devices.

After complete stone removal was achieved, we obtained renal papillary tissue from upper and/or middle calyces using either 3F biopsy forceps (Piranha ${ }^{\mathrm{TM}}$, Boston Scientific; Cup Biopsy Forceps, COOK MEDICAL INC) or BIGopsy ${ }^{\circledR}$ Backloading Biopsy Forceps (COOK MEDICAL INC). Both $\mathrm{RP}$ and normal-appearing papilla tissues were biopsied to compare their RNA profiles.

\section{RNA extraction and analysis}

Intraoperatively, all biopsied samples were immediately preserved in RNAlater ${ }^{\circledR}$ solution (QIAGEN, Hilden, Germany) to stabilize the RNA integrity. Tissue RNA was extracted using either RNA STAT-60 ${ }^{\mathrm{TM}}$ (Tel-Test, Inc., Friendswood, TX) with purification by the RNeasy Mini Kit columns (QIAGEN), or the RNeasy ${ }^{\circledR}$ Micro Kit (QIAGEN) with DNase treatment as per the manufacturer's protocol. To examine the RNA quality and quantity, the extracted genetic specimens were analyzed by NanoDrop ${ }^{\mathrm{TM}}$ (Thermo Fisher Scientific, Waltham, MA) ${ }^{13}$ and Bioanalyzer (Agilent, Santa Clara, CA). The amount of RNA was described as total yield, and the purity of RNA was assessed by the ratios of absorbance at 260 and $280 \mathrm{~nm}$ (A260/A280) as well as 260 and $230 \mathrm{~nm}$ (A260/A230). The degradation of RNA was identified with RNA integrity number (RIN) using Bioanalyzer.

\section{Matched case-control study design}

To examine the clinical impact of tissue biopsy on perioperative outcomes, we conducted a matched case-control study. All URS and PCNL procedures performed during November 2015 through October 2016 were retrospectively reviewed and included in the analysis if postoperative records were available. We utilized the clinical data already captured in ReSKUTM ${ }^{14}$ automated stone registry tied to electronic medical records and REDCap ${ }^{15}$ primarily based at UCSF. Study cases were then matched with control-cases of the same procedure performed without tissue biopsy (case:control=1:2). Matched-pair comparison was for perioperative outcomes including procedure time, blood loss, and postoperative complications.

\section{Statistical analyses}

For the cohort study, two-sample $t$ tests and Mann-Whitney $U$ test were used to identify differences between groups. Categorical variables were compared using Fisher's exact test and Chi-squared test. Correlation between two variables was

Table 1. Characteristics of Patients, Cases, and SPECIMENS Which Biopsied AND EXTRACTED THEIR RNAs

\begin{tabular}{lc}
\hline & $\mathrm{n}=90$ \\
\hline Age, mean \pm SD (y.o.) & $52.4 \pm 15.5$ \\
Gender (\%) & $57(63)$ \\
$\quad$ Male & $33(36)$ \\
Female & $26.7 \pm 6.8$ \\
BMI, mean \pm SD (kg/m²) & \\
Type of tissues (\%) & $44(49)$ \\
Normal & $46(51)$ \\
Randall's plaque & \\
Type of surgery (\%) & $60(67)$ \\
URS & $30(33)$ \\
PCNL & $23(26)$ \\
Type of biopsy forceps (\%) & $67(74)$ \\
3F biopsy forceps & $61[18,122]$ \\
BIGopsy & \\
Duration between sample biopsy & \\
and RNA extraction, & \\
median [25, 75\% IQR], (days) & $28(31)$ \\
RNA Extraction Kit (\%) & $62(69)$ \\
RNA STAT-60 ${ }^{\mathrm{TM}}$ & $675[272,2361]$ \\
RNeasy ${ }^{\circledR}$ Micro Kit & $1.98[1.76,2.04]$ \\
Total yield, median [25, 75\% IQR], (ng) & $6.75[0.25,1.75]$ \\
A260/A280 & $6.39(2.31)$ \\
A260/A230 & \\
RIN, mean \pm SD & \\
\hline
\end{tabular}

$\mathrm{BMI}=$ body mass index; $\mathrm{IQR}=$ interquartile range; $\mathrm{PCNL}=$ percutaneous nephrolithotomy; RIN = RNA integrity number; $\mathrm{SD}=$ standard deviation; y.o. = years old. 
examined by Spearman's rank correlation test. Matched case analysis, as individual matches, was performed by optmatch package. ${ }^{16}$ For the matched case-control study, paired $t$ tests and Wilcoxon signed-rank test were used to identify differences between groups. Categorical variables were compared using Mantel-Haenszel test. Differences were considered statistically significant at $\alpha<0.05$. All statistical analyses were performed with EZR for R (R project). ${ }^{17}$

\section{Results}

A total of 90 renal papilla tissue specimens from 49 patients were collected during the 2-year study period. Patient case and biopsy details are listed in Table 1 . The median total yield, A260/A280 and A260/A230 ratio, and mean RIN of extracted RNAs were $675 \mathrm{ng}, 1.98$ and 0.75 , and 6.39, respectively (Table 1).

The results of univariate analysis are presented as Boxand-Whisker plots in Figure 1. The BIGopsy group demonstrated a significantly higher total RNA yield than the Piranha biopsy forceps group (1320 ng vs $248 \mathrm{ng}, p<0.001)$. The median A260/A280 and A260/A230 ratios were also higher in BIGopsy group (1.99 vs 1.83, $p=0.015$ and 0.99 vs 0.36 , $p=0.047$, respectively). Regarding extraction kits, the RNeasy Micro Kit showed a significantly higher median A260/A230 ratio than RNA STAT-60 group (1.25 vs 0.34 ,
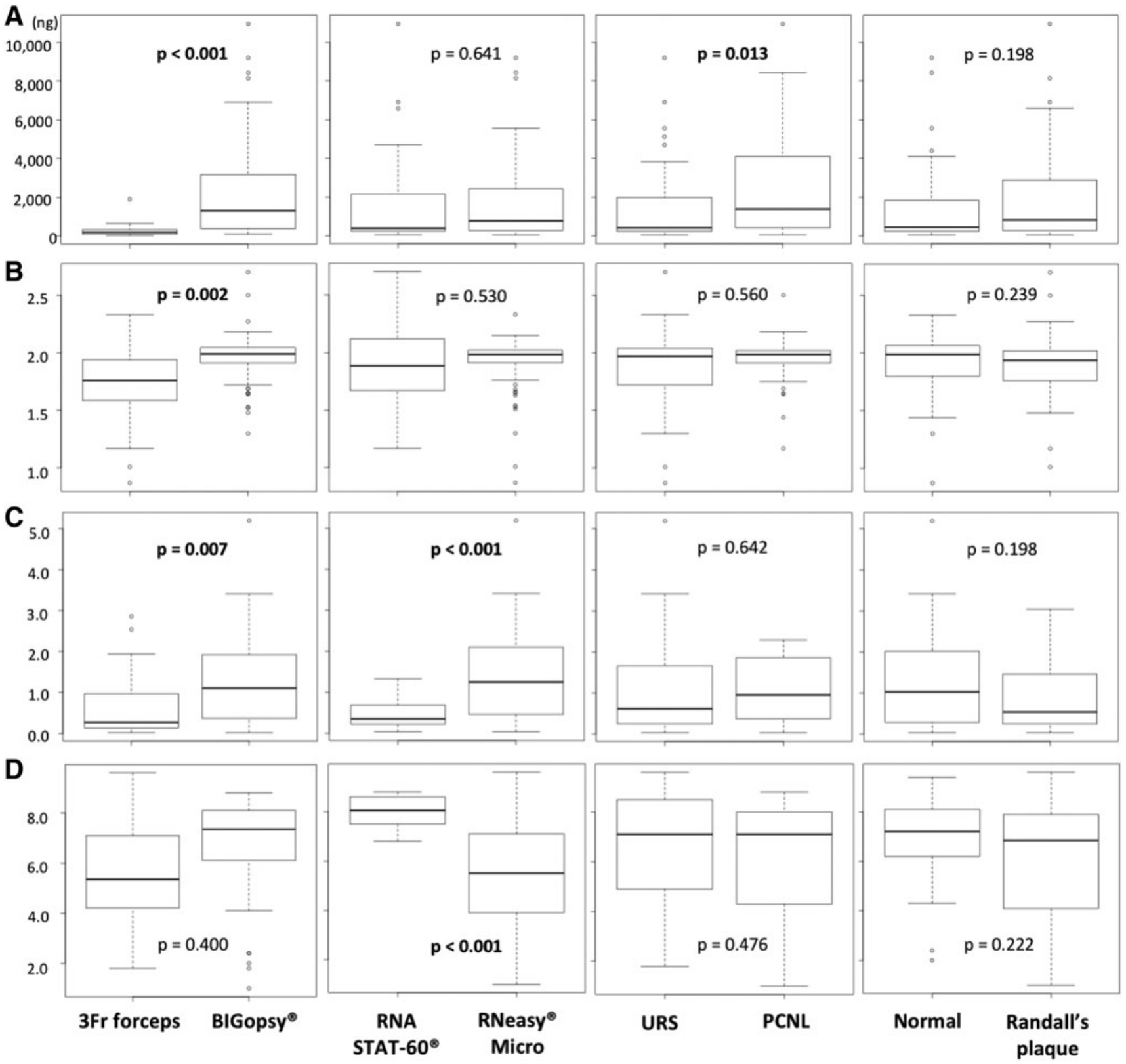

FIG. 1. Box-and-whisker plot comparing total RNA yield (A), A260/A280 (B), A260/A230 (C), and RIN (D) of RNA samples extracted from renal papilla. Analyses were performed by grouping of biopsy forceps, the RNA Extraction Kit, surgery type, and tissue type. Lower and upper quartiles show $25 \%$ and $75 \%$ of ranges among data population. $\mathrm{PCNL}=$ percutaneous nephrolithotomy; RIN = RNA integrity number; URS $=$ ureteroscopy. 

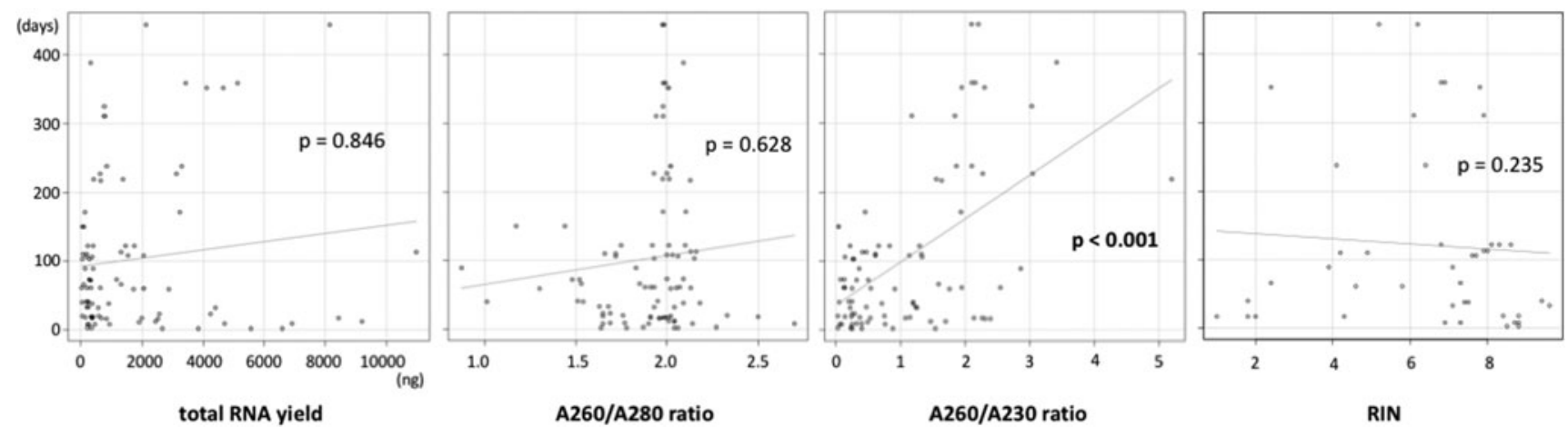

FIG. 2. Correlation scatterplot graphs comparing duration of sample storage with total RNA yield, A260/280, A260/230 ratios, and RIN. Each vertical line indicates the duration of sample storage.

$p<0.001)$. In contrast, the usage of the RNeasy Micro Kit demonstrated a lower mean RIN compared with RNA STAT60 (5.27 vs 8.01, $p<0.001)$. Specimens collected during PCNL had larger total RNA yield compared with those obtained during URS (1393 ng vs $424 \mathrm{ng}, p=0.013$ ). While the duration of sample storage was not significantly correlated to total RNA yield and A260/A280 ratio, it showed a significant correlation to A260/A230 ratio $(p<0.001)$ (Fig. 2).

Table 2 demonstrates multivariate analysis of factors associated with total yield, A260/A280, and A260/A230 ratios of extracted RNA samples. Adjusted for age, gender, body mass index, sample store duration, surgery type, and tissue type, BIGopsy usage produced significantly better total RNA yield, A260/A280, and A260/A230 ratios ( $p=0.004, p=0.001$, and $p=0.004$, respectively). Extraction with the RNeasy Micro Kit usage also showed a positive association with A260/A230 ratio $(p=0.002)$ compared with a negative association with RIN $(p<0.001)$. Case differences between URS and PCNL were associated with neither total yield nor quality of extracted RNA samples.

Hematoxylin-Eosin staining showed that specimens derived from BIGopsy were markedly larger than those derived from Piranha. Microscopically, tissue biopsied by 3F biopsy forceps diffusely lacked urothelial cell layer as well as tubular structures, such as blood vessels and collecting ducts. Moreover, tissue containing RP demonstrated artifactual deterioration of urothelial cells, interstitial cells, and renal tubular cells surrounding the plaque lesion. These findings are contrary to tissue obtained by BIGopsy, in which all vital structures were relatively well preserved (Fig. 3).
In addition to genomic and microscopic structural analysis, we compared clinical outcomes between patients who underwent biopsy and nonbiopsy using a matched case-control study. Table 3 summarizes patient demographics and perioperative characteristics of URS cases comparing between nonbiopsy and biopsy groups. A total of 19 URS and 16 PCNL cases, all of whom had the papilla biopsy performed during the procedures. Total procedure time in the biopsy group was significantly longer than that in the nonbiopsy group (76.6 \pm 21.5 minutes vs $54.8 \pm 22.5$ minutes, $p=0.004)$. There were no significant differences in other perioperative parameters. Table 4 shows patient demographics and perioperative characteristics of PCNL cases in the matched-pair analysis. The total procedure time in the biopsied group was $156.4 \pm 35.1$ minutes, whereas that in the nonbiopsy group was $127.4 \pm 67.4$ minutes $(p=0.114)$. Other parameters were comparable between the two groups.

\section{Discussion}

Since RP was described in $1937,{ }^{18}$ several studies have investigated the importance of this structure but have been limited due to a difficulty in accessing the renal papilla. With advancement in endoscopic instrument design, Low and Stoller reported an endoscopic mapping of RP in kidney stone patients. ${ }^{19}$ Subsequently, Evan and colleagues collected tissue specimens during PCNL and discovered the histopathology of renal tissues surrounding the RP with microstructural analysis. $^{20}$ While several studies have demonstrated safety and feasibility of endoscopic biopsy for histopathological analysis, ${ }^{21}$

Table 2. Multivariate Analysis of Factors Associated with Total Yield, A260/A280, A260/A230, AND RNA INTEGRITY Number OF RNA SPECIMENS

\begin{tabular}{|c|c|c|c|c|c|c|c|c|c|c|c|c|}
\hline & \multicolumn{3}{|c|}{ Total yield } & \multicolumn{3}{|c|}{$A 260 / A 280$} & \multicolumn{3}{|c|}{ A260/A230 } & \multicolumn{3}{|c|}{ RIN } \\
\hline & Coef. & $95 \% C I$ & $\mathrm{p}$ & Coef. & $95 \% C I$ & $\mathrm{p}$ & Coef. & $95 \% C I$ & $\mathrm{p}$ & Coef. & $95 \% C I$ & $\mathrm{p}$ \\
\hline (Intercept) & 2139 & $-1424,5702$ & 0.24 & 1.46 & $1.07,1.86$ & 0 & 0.45 & $-0.76,1.66$ & 0.46 & 12.7 & $7.79,17.7$ & 0 \\
\hline BIGopsy usage & 1857 & 602,3112 & 0.004 & 0.26 & $0.11,0.39$ & 0.001 & 0.63 & $0.21,1.06$ & 0.004 & -1.63 & $-3.96,0.68$ & 0.159 \\
\hline $\begin{array}{l}\text { RNeasy Micro } \\
\text { Kit usage }\end{array}$ & 725 & $-636,2086$ & 0.29 & 0.12 & $-0.03,0.28$ & 0.110 & 0.76 & $0.30,1.23$ & 0.002 & -4.26 & $-6.26,-2.27$ & 0.000 \\
\hline PCNL case & 767 & $-388,1921$ & 0.190 & -0.00 & $-0.13,0.13$ & 0.98 & -0.05 & $-0.44,0.35$ & 0.82 & -0.82 & $-2.56,0.92$ & 0.343 \\
\hline $\begin{array}{l}\text { Randall's } \\
\text { plaque lesion }\end{array}$ & 478 & $-456,1411$ & 0.31 & -0.04 & $-0.14,0.07$ & 0.50 & -0.22 & $-0.54,0.10$ & 0.174 & -0.80 & $-1.97,0.37$ & 0.172 \\
\hline
\end{tabular}

Multivariate model is adjusted for age, gender, BMI, sample store duration before RNA extraction, and variables shown in this table.

Bold values show the figures related to analyses which had been found with statistical differences.

Coef. $=$ coefficient $; 95 \% \mathrm{CI}=95 \%$ confidence interval. 
FIG. 3. Histological comparison of biopsied tissues. Representative microphotographs show HematoxylinEosin stain of renal papillary tip. Asterisk, location of Randall's plaque; black arrow head, urothelial cell layer; white arrow head, mixture of deteriorated urothelial/interstitial/ tubular cells; arrow, collecting ducts. Magnification, $\times 100$. Scale bar, $100 \mu \mathrm{m}$.

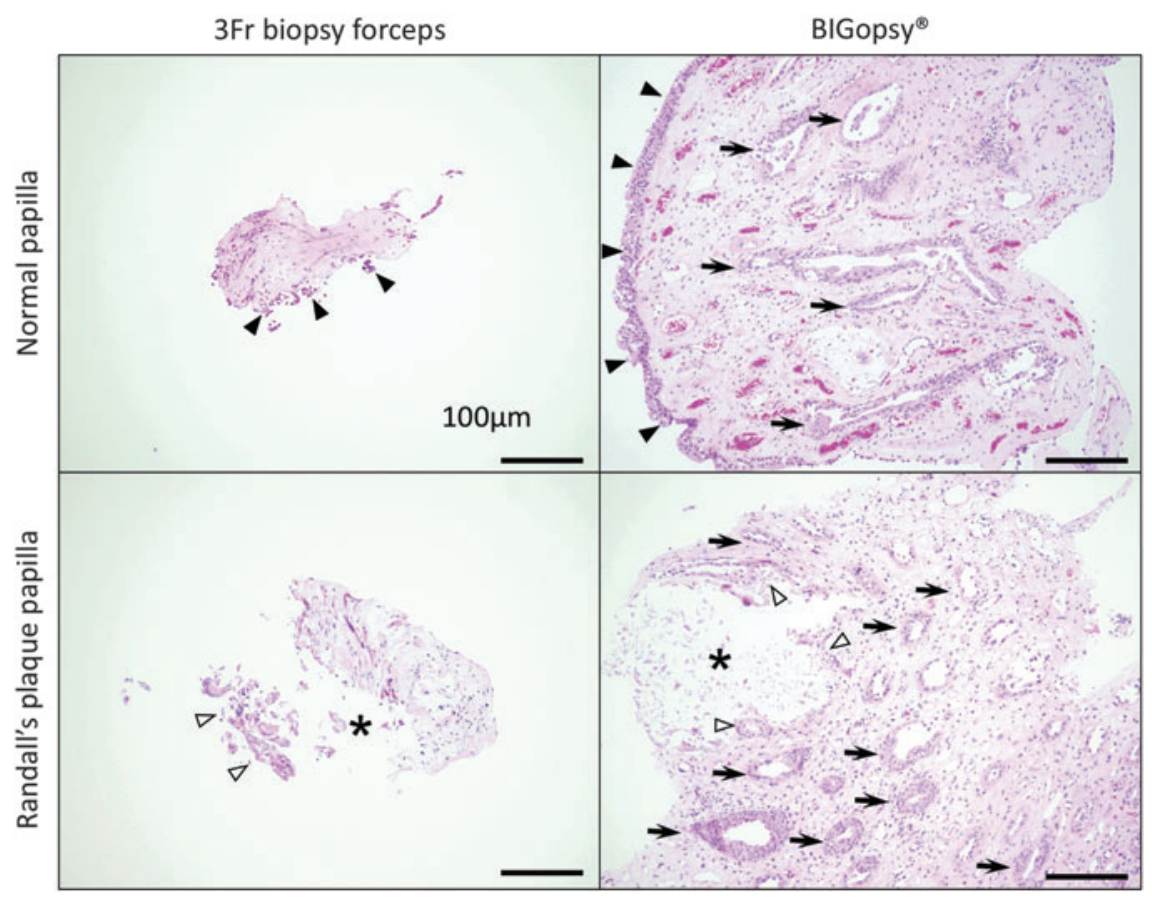

Table 3. Matched-Pair Comparison of Patient and Perioperative Characteristics Between Flexible Ureteroscopy Without Papilla Biopsy and With Biopsy

\begin{tabular}{|c|c|c|c|}
\hline & Nonbiopsy group $(\mathrm{n}=38)$ & Biopsy group $(\mathrm{n}=19)$ & $\mathrm{p}$ \\
\hline Age, mean \pm SD (y.o.) & $53.4 \pm 5.2$ & $51.4 \pm 16.6$ & N.S. \\
\hline Male gender $(\%)$ & $15(40)$ & $6(32)$ & N.S. \\
\hline $\mathrm{BMI}$, mean $\pm \mathrm{SD}\left(\mathrm{kg} / \mathrm{m}^{2}\right)$ & $27.1 \pm 6.1$ & $29.5 \pm 7.7$ & N.S. \\
\hline Bilateral cases $(\%)$ & $6(16)$ & $3(16)$ & N.S. \\
\hline \multicolumn{4}{|l|}{ Stone burden (\%) } \\
\hline$<1 \mathrm{~cm}$ & $23(60)$ & $10(53)$ & \multirow{3}{*}{ N.S. } \\
\hline $1-2 \mathrm{~cm}$ & $11(29)$ & $6(31)$ & \\
\hline$>2 \mathrm{~cm}$ & $4(11)$ & $3(16)$ & \\
\hline Positive urinary culture (\%) & $3(9)$ & $3(19)$ & 0.50 \\
\hline Use of access sheath (\%) & $23(61)$ & $15(83)$ & 0.104 \\
\hline \multicolumn{4}{|l|}{ Endoscopic stone clearance (\%) } \\
\hline Clear & $20(56)$ & $16(84)$ & \multirow[t]{4}{*}{0.168} \\
\hline Only small fragment & $13(36)$ & $2(11)$ & \\
\hline Scheduled to second procedure & $1(3)$ & $1(5)$ & \\
\hline Not applicable & $2(6)$ & $0(0)$ & \\
\hline Postoperative ureteral stent $(\%)$ & $28(74)$ & $18(95)$ & 0.126 \\
\hline Total procedure time, mean \pm SD (min) & $54.8 \pm 22.5$ & $76.6 \pm 21.5$ & 0.004 \\
\hline Blood loss, median $[25,75 \%$ IQR $](\mathrm{mL})$ & $0.0[0.0,5.0]$ & $0.5[0.0,5.0]$ & 0.21 \\
\hline \multicolumn{4}{|l|}{ Postoperative discharge date $(\%)$} \\
\hline POD0 & $31(84)$ & $16(84)$ & \multirow[t]{3}{*}{0.41} \\
\hline POD1 & $4(11)$ & $3(16)$ & \\
\hline POD2 & $2(5)$ & $0(0)$ & \\
\hline \multicolumn{4}{|l|}{ Perioperative complication $^{\mathrm{a}}(\%)$} \\
\hline None & $34(92)$ & $15(79)$ & \multirow[t]{5}{*}{0.16} \\
\hline Grade 1 & $2(5)$ & $1(5)$ & \\
\hline Grade 2 & $0(0)$ & 2 (11) & \\
\hline Grade 3A & 1 (3) & $0(0)$ & \\
\hline Grade 3B & $0(0)$ & $1(5)$ & \\
\hline \multicolumn{4}{|l|}{ Primary stone component (\%) } \\
\hline $\mathrm{CaOx}$ & $19(73)$ & $13(72)$ & \multirow[t]{3}{*}{0.90} \\
\hline UA & $4(15)$ & $2(11)$ & \\
\hline $\mathrm{CaP}$ & $3(12)$ & 3 (17) & \\
\hline
\end{tabular}

The 2:1 matched pair was selected for nonbiopsy (control) and biopsied (intervention) groups, respectively. Both groups were matched by age, gender, BMI, case laterality, and stone burden. Bold values show there is significant difference in the comparison. N.S. means there is no significant differences because of matched-pair analysis.

${ }^{a}$ Surgical complications are graded based on the Clavien-Dindo classification.

$\mathrm{CaOx}=$ calcium oxalate; $\mathrm{CaP}=$ calcium phosphate; $\mathrm{POD}=$ postoperative day; $\mathrm{UA}=$ uric acid. 
Table 4. Matched-Pair Comparison of Patient and Perioperative Characteristics Between Percutaneous Nephrolithotomy Without Papilla Biopsy and With Biopsy

\begin{tabular}{|c|c|c|c|}
\hline & Nonbiopsy group $(\mathrm{n}=32)$ & Biopsy group $(\mathrm{n}=16)$ & $\mathrm{p}$ \\
\hline Age, mean \pm SD (y.o.) & $50.9 \pm 17.7$ & $47.5 \pm 13.2$ & N.S. \\
\hline Male gender $(\%)$ & $15(47)$ & $7(44)$ & N.S. \\
\hline BMI, mean \pm SD $\left(\mathrm{kg} / \mathrm{m}^{2}\right)$ & $27.9 \pm 5.9$ & $31.7 \pm 8.8$ & N.S. \\
\hline Bilateral cases $(\%)$ & $2(6)$ & $2(12)$ & N.S. \\
\hline \multicolumn{4}{|l|}{ Stone burden, $n(\%)$} \\
\hline $1-2 \mathrm{~cm}$ & $8(25)$ & $5(31)$ & \multirow[t]{2}{*}{ N.S. } \\
\hline$>2 \mathrm{~cm}$ & $24(75)$ & $11(69)$ & \\
\hline Positive urinary culture (\%) & $7(28)$ & $4(33)$ & 0.86 \\
\hline \multicolumn{4}{|l|}{ Endoscopic stone clearance (\%) } \\
\hline Clear & $27(84)$ & $14(88)$ & \multirow[t]{4}{*}{0.74} \\
\hline Only small fragment & $2(6)$ & $1(6)$ & \\
\hline Scheduled to second procedure & $1(3)$ & $1(6)$ & \\
\hline Not applicable & $2(6)$ & $0(0)$ & \\
\hline Total procedure time, mean $\pm \mathrm{SD}(\min )$ & $127.4 \pm 67.4$ & $156.4 \pm 35.1$ & 0.114 \\
\hline Blood loss, median $[25,75 \%$ IQR $](\mathrm{mL})$ & $50[50,113]$ & $50[28,50]$ & 0.093 \\
\hline \multicolumn{4}{|l|}{ Postoperative discharge date $(\%)$} \\
\hline POD1 & $15(47)$ & $8(50)$ & \multirow[t]{3}{*}{0.82} \\
\hline POD2 & $14(44)$ & $8(50)$ & \\
\hline$\geq$ POD3 & $3(9)$ & $0(0)$ & \\
\hline \multicolumn{4}{|l|}{ Perioperative complication ${ }^{\mathrm{a}}(\%)$} \\
\hline None & $25(81)$ & $11(73)$ & \multirow[t]{3}{*}{0.183} \\
\hline Grade 1 & $1(3.2)$ & $3(20)$ & \\
\hline Grade 2 & $5(16)$ & $1(7)$ & \\
\hline Decrease of Hct, median [25, 75\% IQR] (\%) & $2.7[1.7,3.4]$ & $2.4[1.8,3.7]$ & 0.68 \\
\hline Increase of $\mathrm{Cr}$, median $[25,75 \% \mathrm{IQR}](\mathrm{mg} / \mathrm{dl})$ & $0.01[-0.05,0.06]$ & $-0.02[-0.04,0.02]$ & 0.93 \\
\hline \multicolumn{4}{|l|}{ Residual stone $(\%)$} \\
\hline None & $25(78)$ & $13(87)$ & \multirow{3}{*}{0.80} \\
\hline$<10 \mathrm{~mm}$ & $4(13)$ & $2(13)$ & \\
\hline$>20 \mathrm{~mm}$ & $3(9)$ & $0(0)$ & \\
\hline \multicolumn{4}{|l|}{ Primary stone component $(\%)$} \\
\hline $\mathrm{CaOx}$ & $15(50)$ & $9(69)$ & \multirow{4}{*}{0.39} \\
\hline UA & $4(13)$ & $1(8)$ & \\
\hline Struvite & $3(10)$ & $1(8)$ & \\
\hline $\mathrm{CaP}$ & $8(27)$ & $2(15)$ & \\
\hline
\end{tabular}

The 2:1 matched pair was selected for nonbiopsy (control) and biopsied (intervention) groups, respectively. Both groups were matched by age, gender, BMI, case laterality, and stone burden. N.S. means there is no significant differences because of matched-pair analysis.

${ }^{a}$ Surgical complications are graded based on the Clavien-Dindo classification.

few studies have confirmed them for genomic study. Nextgeneration gene sequencing technology holds the potential of unlocking the genetic triggers for stone formation, but fundamental to initiating these studies is establishing effective tissue collection protocols. Compared with prior studies, our work focused on not only tissue quality obtained by endoscopic biopsy, but also the clinical safety of biopsies.

Obtaining high-quality RNA from a tiny biopsied specimen was challenging and needed to be standardized. Typical RNA sequencing needs at least 200 ng of RNA, sufficiently $1 \mu \mathrm{g}$ of total RNA for purification, quality check, and libraries. ${ }^{22}$ RNA absorbance spectrum is also important as a marker of quality. In general, an A260/A280 ratio of 1.8 to 2.0 and A260/A230 ratio of 1.8 to 2.2 are considered as pure, high-quality RNA. ${ }^{23}$ These quantity and quality of extracted RNA products are essential to gain solid results from gene expression analyses with RNA sequencing.

From 90 renal papilla tissues analyzed in this study, quantitative analysis resulted in a median total RNA yield of $675 \mathrm{ng}$, which is usually reasonable, but still not sufficient for both RNA sequence and microarray. The median A260/A280 ratio was 1.98, whereas the median A260/A230 ratio and mean RIN were 0.75 and 6.39 , respectively. The low ratio of A260/A230 suggested a high absorbance at $230 \mathrm{~nm}$, possibly from contamination of carbohydrate, phenol, or guanidine as per the manufacturer's guideline. ${ }^{13}$ While some samples demonstrated degradation and low RNA quality, subsequent preliminary examination of 24 samples from this study showed that only one sample failed to complete RNA library preparation. These findings emphasize the importance of RNA extraction protocol improvement to obtain larger amount and higher quality of RNA derived from biopsied tissue specimens.

We used RNAlater to store all samples until extracting RNA for gene expression profiling study. Prior studies $^{24,25}$ have shown the efficacy of RNAlater for tissue preservation, especially to maintain RNA integrity over a long storage duration. Enough RNA yield was obtained from these tissue specimens; however, their microstructures for routine histological examination were not adequate. ${ }^{25}$ In this study, we stored tissue specimens immediately after biopsy at room temperature, then moved them to $4^{\circ} \mathrm{C}$ overnight, and finally kept them at $-80^{\circ} \mathrm{C}$. The median duration of sample storage before RNA extraction was 61 days. Given that we stored the 
specimens in a better condition but in a similar duration compared with the prior study, our specimen handling protocol could be more appropriate for gene expression profiling study. Moreover, there were no significant correlations between sample storage duration and total RNA yield or even A260/A280 ratio. In contrast, a significant correlation between sample storage duration and A260/A230 ratio has been demonstrated. Since this finding suggested that even longer duration of sample storage could result in high RNA quality, the sample preservation with RNAlater mitigated the degradation of RNA during the storage.

BIGopsy forceps are designed for obtaining bigger specimen compared with traditional biopsy forceps by using a $2.4 \mathrm{~F}$ cup. Since the tip size is larger than the working channel of a ureteroscope, it has to be backloaded into the scope before its usage, and usually requires usage of ureteral access sheath for most cases to mitigate interference with scope view. This backloading process may influence ureteroscope durability, but this factor was neither assessed in the current study nor has it been the subject of previous publications. ${ }^{26}$ Prior studies described that tissues derived from BIGopsy forceps had threefold longer diameter and showed more accurate histopathological features than those from $3 \mathrm{~F}$ biopsy forceps. ${ }^{26,27}$ In this study, using a BIGopsy forceps significantly increased total RNA yield, A260/A280 and A260/A230 ratios, and these findings still held true from further univariate and multivariate analyses. Comparing tissue specimens taken from the two different forceps, Hematoxylin-Eosin stain indicated that BIGopsy forceps preserved a structure of RPs as well as urothelial cell layers, collecting ducts, and blood vessels. These larger RNA yields and preservation of cell structure by BIGopsy forceps may have provided the better quality of extracted RNA. Utilizing BIGopsy forceps could facilitate a successful RNA extraction by providing larger, deeper, and well-preserved specimens.

The multivariate analysis revealed the usage of the RNeasy Micro Kit improved 0.76 of A260/A230 of RNA. As per the manufacturer's guideline, the RNeasy Micro Kit is appropriate for extracting a small amount of RNA up to $45 \mu \mathrm{g}$. Previous study in laser-capture microdissected prostate tissue has demonstrated that the RNeasy Micro Kit generated the highest RNA quality compared with other extraction kits. ${ }^{28}$ However, the RNeasy Micro Kit also showed degradation of RNA as indicated by relatively low RIN. One possible explanation for this result might be that our RNA extraction protocol with the RNeasy Micro Kit did not utilize a purification step. We elected to use this protocol given that purification using extra sets of column extraction could reduce the amount of extracted RNA resulting in a low A260/A230 ratio, despite decreased RNA degradation. The usage of an appropriate extraction kit with thorough protocol is extremely important to conduct a genomic study. For procedural type, our univariate analysis showed that tissue obtained during PCNL cases had greater total RNA yield than those obtained during URS cases. One might think that a rigid nephroscope would provide better instrument accessibility for renal papillary tissue biopsy and a higher chance to obtain a larger tissue piece compared with a flexible ureteroscope given its larger working channel. However, multivariate analysis failed to demonstrate statistical differences between sample quality and quantity from PCNL and URS cases. To address this hypothesis, further study comparing tissue size derived from different endoscopic surgeries is needed.
From a clinical standpoint, we confirmed the safety of renal papilla biopsy during endoscopic stone treatments through a matched case-control analysis comparing nonbiopsy to biopsy patients. Earlier study reported that tissue biopsy during URS and PCNL was safe and provided specimens sufficient for histological examination. ${ }^{21}$ Likewise, our study has shown comparable clinical outcomes, including blood loss, complication rate, stone-free status, and hospital stay. However, one downside of performing intraoperative biopsy was a longer procedure time, which appeared exclusively in URS cases. Several reasons may explain this finding. BIGopsy requires a backload assembly from the tip to the working channel of the ureteroscope for each device passage. Since this device was used in most cases of our study, it may contribute to the longer procedure time found in URS cases. Another study has demonstrated that BIGopsy reduces irrigation flow rate, scope deflection, and collecting system visualization. ${ }^{29}$ Given that multivariate analysis showed no differences of RNA yield and quality between URS and PCNL, biopsy during URS remains a useful approach to collect tissue samples. URS is less invasive than PCNL and a procedure used with higher prevalence. It is also used for smaller stone burdens and tissue removed during these cases may reflect different severity of disease states compared with PCNL. As such, tissue obtained during URS remains complementary compared with that obtained during PCNL.

Some limitations in this study need to be addressed. Regarding the multi-institutional nature, differences within each institution's environment were unavoidable. They included different surgeons, equipment, and even distance between the operative room and the research laboratory, and could affect the result of RNA extraction. In addition, this study enrolled a relatively small number of biopsy cases, which might not be meaningful enough to compare with nonbiopsy cases if larger studies are performed. Furthermore, our methodology has yet to be validated in an actual genomic study. Genomic analyses using RNA extracted with the technique outlined in this current study are necessary to validate the protocol. If proven valid, however, our study would open the door to nextgeneration genomic study of the renal papilla.

\section{Conclusions}

Utilizing BIGopsy forceps significantly improved both RNA yield and quality of renal papillary tissues obtained from endoscopic biopsy. While tissue biopsy during URS significantly prolonged the procedure time, it was minimally invasive and clinically safe. These findings will facilitate future genomic studies and lead to a better understanding of kidney stone formation.

\section{Acknowledgments}

This work was supported by the educational grant from the Boston Scientific Foundation (T.C.), the U.S. National Institutes of Health with grants K12-DK-07-006 (T.C.), P20DK-100863 (M.L.S., T.C.), JSPS KAKENHI Grant No. 16K11054 (K.T., T.Y.), The Naito Foundation Research Grant (K.T.), and The Mochida Memorial Foundation for Medical and Pharmaceutical Research (K.T.). The sponsors played no direct role in the study. 


\section{Author Disclosure Statement}

Marshall L. Stoller and Thomas Chi serve as paid speakers and consultants for Boston Scientific Corporation and have received educational grant funding from Richard Wolf. Marshall L. Stoller has served as a paid speaker for the Karl Storz Company.

\section{References}

1. Sorokin I, Mamoulakis C, Miyazawa K, et al. Epidemiology of stone disease across the world. World J Urol 2017;1-20.

2. Khan SR, Pearle MS, Robertson WG, et al. Kidney stones. Nat Rev Dis Primers 2016;2:16008.

3. Yasui T, Okada A, Hamamoto S, et al. Pathophysiologybased treatment of urolithiasis. Int J Urol 2017;24:32-38.

4. Türk C, Petrrík A, Sarica K, et al. EAU Guidelines on Interventional Treatment for Urolithiasis. Eur Urol 2016;69: 475-482.

5. Assimos D, Krambeck A, Miller NL, et al. Surgical Management of Stones: American UrologicalAssociation/ Endourological Society Guideline, PART II. J Urol 2016; 196:1161-1169.

6. Giusti G, Proietti S, Villa L, et al. Current standard technique for modern flexible ureteroscopy: Tips and tricks. Eur Urol 2016;70:188-194.

7. Linnes MP, Krambeck AE, Cornell L, et al. Phenotypic characterization of kidney stone formers by endoscopic and histological quantification of intrarenal calcification. Kidney Int 2013;84:818-825.

8. Borofsky MS, Paonessa JE, Evan AP, et al. A proposed grading system to standardize the description of renal papillary appearance at the time of endoscopy in patients with nephrolithiasis. J Endourol 2016;30:122-127.

9. Taguchi K, Hamamoto S, Okada A, et al. Genome-wide gene expression profiling of Randall's plaques in calcium oxalate stone formers. J Am Soc Nephrol 2017;28:333-347.

10. Zuo L, Tozawa K, Okada A, et al. A paracrine mechanism involving renal tubular cells, adipocytes and macrophages promotes kidney stone formation in a simulated metabolic syndrome environment. J Urol 2014;191:1906-1912.

11. Koul S, Khandrika L, Meacham RB, et al. Genome wide analysis of differentially expressed genes in HK-2 cells, a line of human kidney epithelial cells in response to oxalate. PLoS One 2012;7:e43886.

12. Tzou DT, Taguchi K, Chi T, et al. Animal models of urinary stone disease. Int J Surg 2016;36:596-606.

13. Desjardins P, Conklin D. NanoDrop microvolume quantitation of nucleic acids. J Vis Exp 2010;45.

14. Chang HC, Tzou DT, Usawachintachit M, et al. Rationale and design of the Registry for Stones of the Kidney and Ureter (ReSKU): A prospective observational registry to study the natural history of urolithiasis patients. J Endourol 2016;30:1332-1338.

15. Harris PA, Taylor R, Thielke R, et al. Research electronic data capture (REDCap) - A metadata-driven methodology and workflow process for providing translational research informatics support. J Biomed Inform 2009;42:377-381.

16. Daniel SR, Armstrong K, Silber JH, et al. An algorithm for optimal tapered matching, with application to disparities in survival. J Comput Graph Stat 2008;17:914-924.

17. Kanda Y. Investigation of the freely available easy-to-use software "EZR" for medical statistics. Bone Marrow Transplant 2013;48:452-458.
18. Randall A. The origin and growth of renal calculi. Ann Surg 1937;105:1009-1027.

19. Low RK, Stoller ML. Endoscopic mapping of renal papillae for Randall's plaques in patients with urinary stone disease. J Urol 1997;158:2062-2064.

20. Evan AP, Lingeman JE, Coe FL, et al. Randall's plaque of patients with nephrolithiasis begins in basement membranes of thin loops of Henle. J Clin Invest 2003;111:607-616.

21. Ruggera L, Gambaro G, Beltrami P, et al. Percutaneous and transureteral biopsies of renal papillae: Safe and appropriate procedures for in vivo histologic analysis in stone formers. J Endourol 2011;25:25-30.

22. Mantione KJ, Kream RM, Kuzelova H, et al. Comparing bioinformatic gene expression profiling methods: Microarray and RNA-Seq. Med Sci Monit Basic Res 2014;20: 138-142.

23. Gayral P, Weinert L, Chiari Y, et al. Next-generation sequencing of transcriptomes: A guide to RNA isolation in nonmodel animals. Mol Ecol Resour 2011;11:650-661.

24. Camacho-Sanchez M, Burraco P, Gomez-Mestre I, et al. Preservation of RNA and DNA from mammal samples under field conditions. Mol Ecol Resour 2013;13:663-673.

25. Roos-van Groningen MC, Eikmans M, Baelde HJ, et al. Improvement of extraction and processing of RNA from renal biopsies. Kidney Int 2004;65:97-105.

26. Wason EL, Seigne JD, Schned AR, et al. Ureteroscopic biopsy of upper tract urothelial carcinoma using a novel ureteroscopic biopsy forceps. Can J Urol 2012;19:6560-6565.

27. Al-Qahtani SM, Legraverend D, Gil-Diez de Medina S, et al. Can we improve the biopsy quality of upper urinary tract urothelial tumors? Single-center preliminary results of a new biopsy forceps. Urol Int 2014;93:34-37.

28. Kolijn K, van Leenders GJ. Comparison of RNA extraction kits and histological stains for laser capture microdissected prostate tissue. BMC Res Notes 2016;9:17.

29. Ritter M, Bolenz C, Bach T, et al. Standardized ex vivo comparison of different upper urinary tract biopsy devices: Impact on ureterorenoscopes and tissue quality. World $\mathbf{J}$ Urol 2013;31:907-912.

Address correspondence to:

Thomas Chi, $M D$

Department of Urology

University of California, San Francisco 400 Parnassus Avenue, Sixth Floor, Suite A610

San Francisco, CA 94143

E-mail: tom.chi@ucsf.edu

$\begin{aligned} & \text { Abbreviations Used } \\ & \text { ASA }=\text { American Society of Anesthesiologists } \\ & \text { NCU }=\text { Nagoya City University } \\ & \text { PCNL }=\text { percutaneous nephrolithotomy } \\ & \text { REDCap }=\text { Research Electronic Data Capture } \\ & \text { ReSKU }=\text { the Registry for Stones of the Kidney and Ureter } \\ & \text { RIN }=\text { RNA integrity number } \\ & \text { RP }=\text { Randall's plaque } \\ & \text { UCSF }=\text { University of California San Francisco } \\ & \text { URS }=\text { ureteroscopy }\end{aligned}$

